\title{
Weekly work planner
}

Building a custom weekly plan that will help us to keep on top of our work. Add your classes, work commitments and clubs first, then block out space every week to complete assignments and reading - then stick to this, don't try more, and don't do less.

\begin{tabular}{|c|c|c|c|c|c|c|c|}
\hline Time & Mon & Tues & Wed & Thurs & Fri & Sat & Sun \\
\hline $6-7$ & & & & & & & \\
\hline $7-8$ & & & & & & & \\
\hline $8-9$ & & & & & & & \\
\hline $9-10$ & & & & & & & \\
\hline $10-11$ & & & & & & & \\
\hline $11-12$ & & & & & & & \\
\hline $12-13$ & & & & & & & \\
\hline $13-14$ & & & & & & & \\
\hline $14-15$ & & & & & & & \\
\hline $15-16$ & & & & & & & \\
\hline $16-17$ & & & & & & & \\
\hline $17-18$ & & & & & & & \\
\hline $18-19$ & & & & & & & \\
\hline $19-20$ & & & & & & & \\
\hline $20-21$ & & & & & & & \\
\hline $21-22$ & & & & & & & \\
\hline $22-23$ & & & & & & & \\
\hline $23-00$ & & & & & & & \\
\hline
\end{tabular}

A supplementary resource of The Media and Communications Study Skills Student Guide by Doug Specht. Available to buy or download free here: https://www.uwestminsterpress.co.uk/site/books/10.16997/book42 


\section{Article Summarizing Sheet}

A good way to start taking notes for an essay or other assignment is to make summaries, in your own words, of the things you have read. This will help you build up a body of information that you can then start to synthesize into paragraphs and arguments. Use the questions from the book to help.

Title of article:

Authors of article:

Main Argument:

Summary of article (in your own words):

Full reference: 


\section{Seminar Discussion Self Assessment}

Seminars are where most of your learning at university will take place, so as part of your seminar experience it can be useful to reflect on the way in which you contributed and engaged with the session. Try making notes about the following questions and over the course of your degree move towards having more yes's than no's in the final column.

\section{Did you?...}

Contribute to the discussion by giving your opinion?

Give reasons and justify your opinions?

Listen and respond to others?

Express agreement and disagreement in an appropriate way?

Refer to any of the points from the pre-class reading?

Encourage other group members to talk?

Yes

No

Yes

No

Yes

No

Yes

No

es

No

Yes

No

A supplementary resource of The Media and Communications Study Skills Student Guide by Doug Specht. Available to buy and download free here: https://www.uwestminsterpress.co.uk/site/books/10.16997/book42 


\section{Checking Your Work}

Proofreading your work is a really important part of writing. However, it isn't just about spelling and grammar, you also need to check that your argument and structure are solid too. Use the questions below to make notes and you reread your own work, and then use these notes to make improvements.

\section{Introduction.}

Is it clear? Would the reader understand what the essay is about?

\section{Stance/line of argument}

Is this clear, does it make sense? Is it consistent throughout the text. Is it too strong or too weak?

\section{Coherence and cohesion.}

Is the language clear. Is there cohesion at sentence and paragraph level?

\section{Conclusion}

Is the conclusion logical? Does it answer the question? Does it follow the flow of the rest of the writing?

\section{Grammar and vocabulary.}

Is the grammar accurate? Was the use of vocabulary appropriate and accurate?

\section{References}

Are in-text citations formed properly? Is the reference list formed to the correct, alphabetical style?

\section{Over all}

Does the essay hold together? Is it the correct length? Is it formatted correctly? Check how it is submitted. 


\section{Preparing a Literature Review}

When you are writing a literature review it is important that you are able to give a broad overview of work in the subject area, while also staying focused on your research questions. Use the form below as you are reading to help you organize notes and to spot any gaps in your reading.

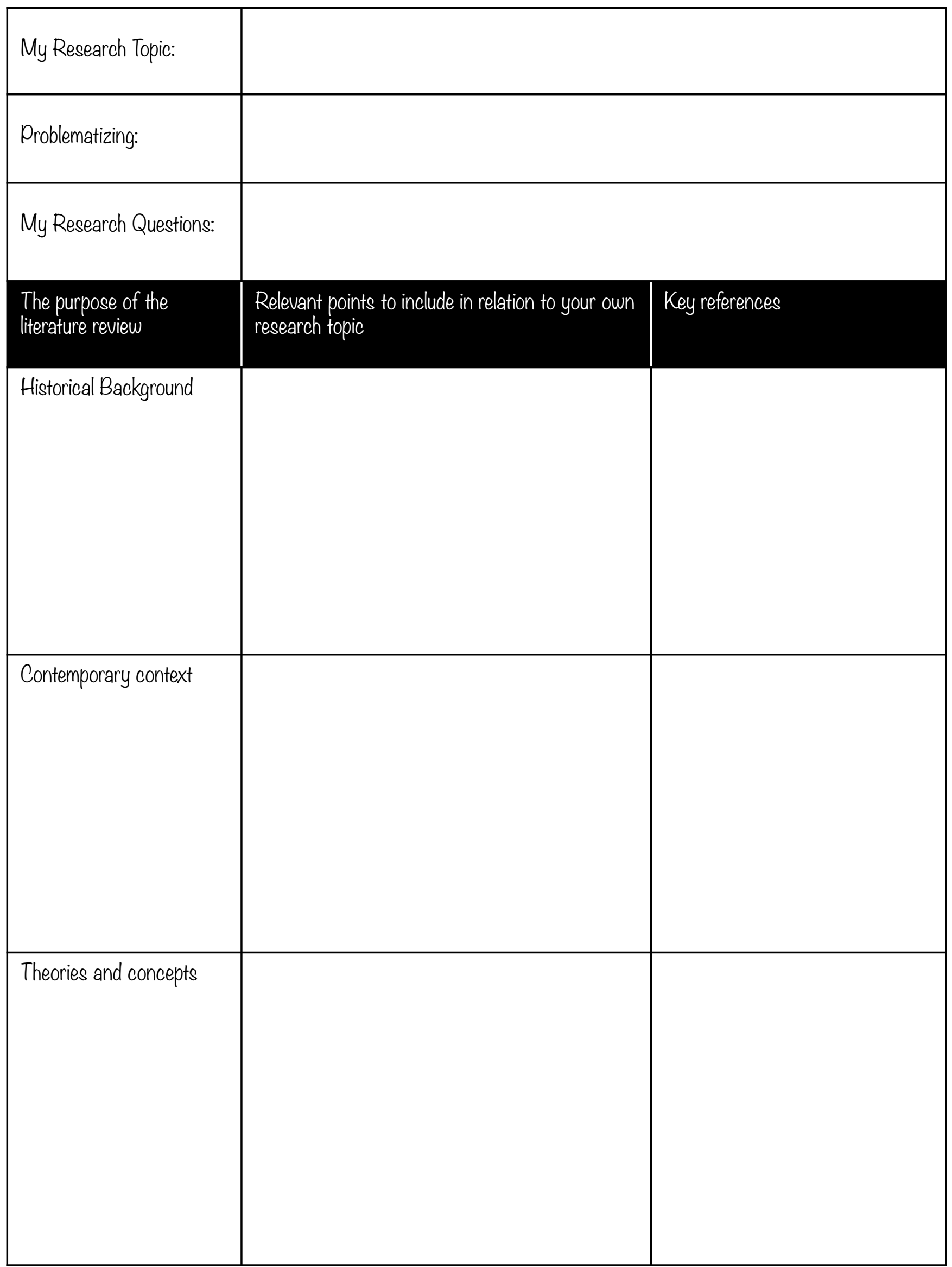




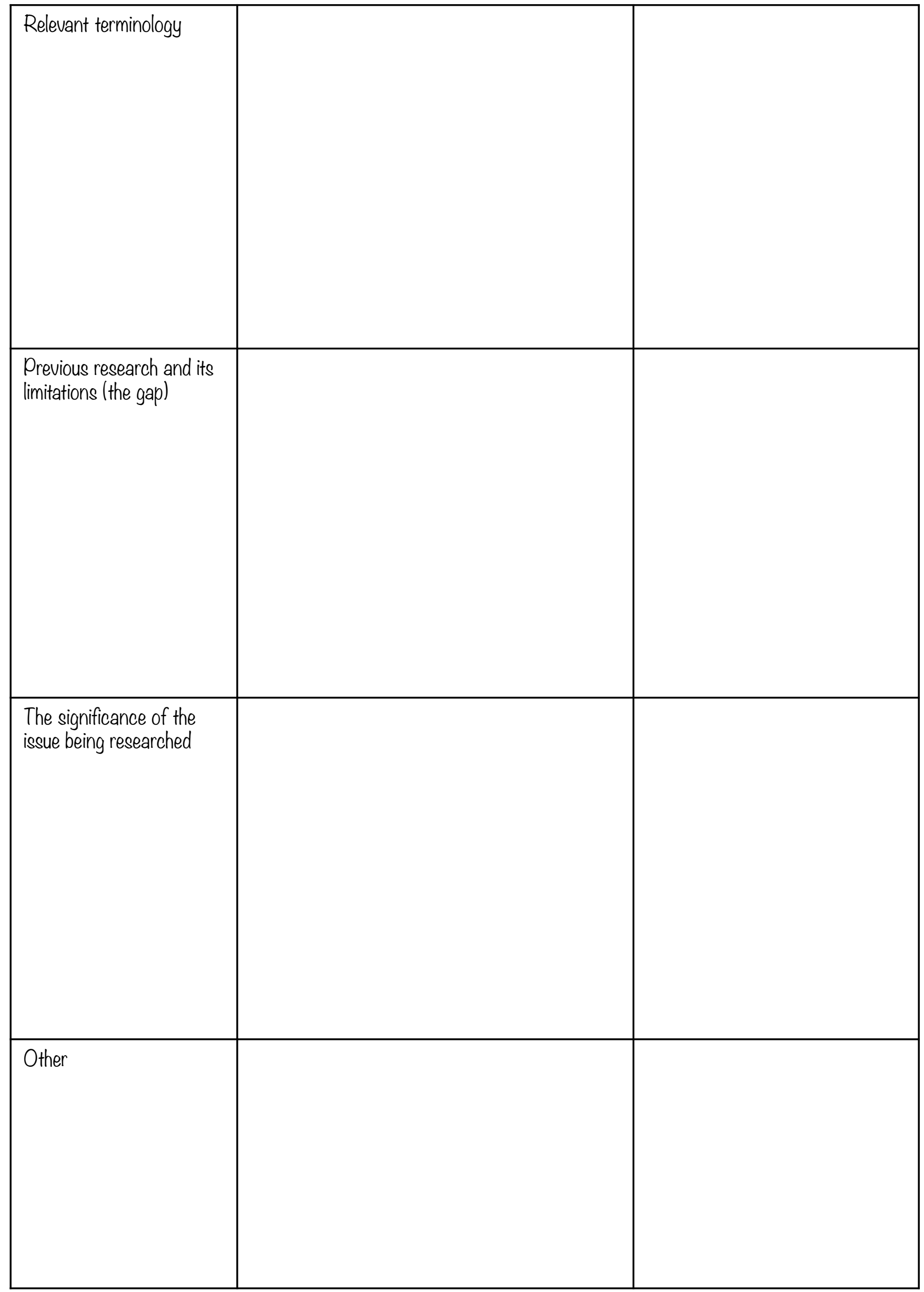

A supplementary resource of The Media and Communications Study Skills Student Guide by Doug Specht. Available to buy and download free here: https://www.uwestminsterpress.co.uk/site/books/10.16997/book42 


\section{Self Evaluation}

Self evaluation, or reflection, is a really good way of helping you to get the most from your studies. Think about the things that you do well, and those things you want to improve. Write this below and keep it safe. At the end of the semester see how you have done, and set fresh goals ready for the new semester.

General strengths:

Points for improvement:

Areas to work on, and how to achieve this.: 